\title{
USING SATELLITES TO MONITOR SEVERN BRIDGE STRUCTURE, UK
}

\author{
G. W. Roberts ${ }^{a^{*}}$, C. J. Brown ${ }^{b}$, X. Tang ${ }^{\text {a }}$, O. Ogundipe ${ }^{c}$ \\ ${ }^{\text {a }}$ Faculty of Science and Engineering, The University of Nottingham Ningbo China \\ ${ }^{\mathrm{b}}$ School of Engineering and Design, Brunel University, London, UK \\ ${ }^{c}$ Nottingham Geospatial Institute, The University of Nottingham, UK.
}

KEY WORDS: Bridges, Research \& development, Field Testing \& Monitoring

\begin{abstract}
:
The Severn Bridge is a suspension bridge, in total 1,600m long with a main span of $988 \mathrm{~m}$ and tower heights of $136 \mathrm{~m}$.

In 2010, a series of field surveys were commissioned to monitor the magnitude and frequencies of the Severn Suspension Bridge's movements, through attaching 9 dual-frequency survey grade GNSS receivers on the Bridge, and two reference GNSS stations located adjacent to the structure. The bridge's GNSS receivers were attached to the tops of the two pairs of towers, as well as 5 GNSS antennas attached directly onto the suspension cables. Four were attached at various locations on the Northern cable, and one on the southern cable.

The GNSS antenna locations and configuration allows the movements of the north cable to be analysed at 4 locations, as well as the differential movements of the two suspension cables to each other. In addition, this configuration allows the movements of the tops of the towers to be compared to the cables' movements, as well as with each other. All in all, allowing the relative movements of the various locations on the bridge's suspension cables and tower tops to be compared to each other, at a rate of up to $20 \mathrm{~Hz}$.
\end{abstract}

Overall, some 3 days of raw code and carrier phase GNSS data were gathered. During these sessions, normal traffic loading was experienced. This paper describes the survey, presents a selection of the key results and draws conclusions about the effective use of GNSS to enhance structural health monitoring. 


\section{INTRODUCTION}

The use of GPS (Global Positioning System) and GNSS (Global Navigation Satellite Systems) to monitor the movements of bridge structures has been an ongoing area of research by the principal authors for over 18 years [Ashkenazi et al., 1996; Ashkenazi et al., 1997; Brown et al., 1999; Roberts et al., 2000]. The authors' work started on the Humber Bridge [Ashkenazi et al., 1997], and then moved onto the Millennium Bridge in London [Roberts et al., 2006], the Wilford Bridge in Nottingham [Meo et al., 2004], the Forth Road Bridge [Roberts et al., 2012], the Avonmouth M5 crossing [Ogundipe et al., 2012] and now the M48 Severn Suspension Bridge [Roberts et al., 2010]. Historically the authors have clamped the GPS/GNSS antennas onto the parapet on the side of the bridge, and on the parapets at the tops of the towers [e.g. Roberts et al., 2004a]. However this latest work on the Severn Bridge sees the GNSS antennas attached directly to the suspension cables, in addition to the tops of the towers. Locating the GNSS antennas directly onto the suspension cables is thought to be the first time this has been carried out to this extent. The Tsing Ma Bridge in Hong Kong has 14 GPS receivers permanently located upon it, mainly on the bridge deck and tower tops. However, there are two GPS antennas, one on each of the two suspension cables, located at the middle of the main span [Wong et al., 2001]. The Xihoumen Bridge near Ningbo China, boasts the second longest suspended span in the World, at $1,650 \mathrm{~m}$. This bridge is equipped with 18 GPS receivers located on the tops of the towers and on the bridge, 7 tilt meters on each of the two support towers, further tilt sensors on the bridge deck to measure torsional movements, strain gauges built in to the cables, as well as anemometers and thermometers.

The scientific principles involved have not changed since the beginning of the application of GPS to structural movement [Roberts, 1997]. In essence, the use of dual frequency receivers with the existing satellite geometries would not, in itself, enable sufficiently accurate results to be obtained. However, when the results are processed relative to a nearby stationary GNSS receiver located over a position with a known coordinate (and preferably more than one to ensure redundancy) then sufficient accuracy and precision can be obtained. In addition to which, the carrier phase of the signal is used, rather than the code; which is used by most navigation GNSS receivers [HofmannWellenhof et al., 2003; Hofmann-Wellenhof et al., 2008]. Furthermore, the quality of the receivers has improved and the cost decreased over time, and while the commercial demand for such receivers is not high, there is sufficient decrease in cost for the processes to become realistic for engineering purposes. The accuracy and precision of the application of GNSS in this way surprises many; 3-dimensional sub-centimetre accuracy and precision is readily available and, as the results in this paper will show, better data analysis leads to even greater accuracy and precision than that. The resolution and expected accuracies and precision have been previously reported by the authors at millimetre level [Roberts et al., 2012]. These previous results illustrate that the resolution of the satellite ranges can be of the order of sub-mm in computed values [Roberts et al., 2012; Roberts, 1997.

There are several reasons why GNSS can be the most appropriate technology for monitoring the deflections of such large structures, and hence provide useful information for a Structural Health Monitoring (SHM) system. First, the measurement of small movements on a large bridge structure can be logistically very awkward to say the least through using other methods. While other surveying techniques have also developed in recent years, each has difficulties when applied to the tall towers or the cables of a large suspension bridge, located a couple of kilometres away from stable land. GNSS antennas can be placed anywhere with line of sight to satellites. Once placed, their position will be measured at a relatively high frequency $-20 \mathrm{~Hz}$ is now typical - giving not only absolute position and movement, but also the frequencies up to the Nyquist frequency of $10 \mathrm{~Hz}$. Processing the data is a relatively straightforward procedure. The main advantage is that it gives an 
overall position/movement assessment of the structure relative to a permanently repeatable position in space, and means that a repeated assessment can be made over long elapsed time periods, identifying both long-term trends and changes in behaviour.

While the authors have developed strategies for the assessment of behaviour [Ogundipe at al., 2012; Roberts et al., 2012] there have been various attempts by others to identify particular events from the extended range of data available. Data analysis techniques have been adopted but Ogaja et al. (2002) and Rizos \& Han (1998) point out the fundamental that GPS is appropriate for measuring the global performance of a structure, while other techniques are probably more appropriate to measure local changes in behaviour.

In the case of a large suspension bridge, a change (probably reduction) in global stiffness of $1 \%$ potentially well into the GNSS detectable range -implies a more major change to the physical condition of the structure. In structures with greater levels of redundancy, it is conceivable that significant local damage may occur without detectable change to the global performance.

These arguments suggest that the use of techniques such as strain gauging, or acoustic emission is unlikely to be able to provide a complete structural health monitoring system. Conversely GNSS will give measurements of displacement and frequency at selected positions around the structure, and would be appropriate as part of a wider monitoring system.

Recent work by the authors illustrated a change in the natural frequency of the Forth Road Bridge was detected in the GPS data during peak and quiet periods of traffic loading. The change was correlated well with the extra weight of the traffic on the bridge [Brown et al. 2007].

To be effective it is important to develop a datum for subsequent monitoring. New structures are rarely monitored, and for any SHM system to be effective it is important that comparisons are made to the "as-built" or "in-service" conditions. The use of GNSS for structural monitoring is now widespread, and it is noticeable that GNSS receivers are fitted to nearly all new major structures in Eastern Asia as a matter of course [Liu, 2013; Jiang et al., 2002; Yue et al., 2013]. However, it is less clear whether full use of the GPS data is made in terms of analysing the movements and deriving the frequencies of the movements, as well as comparing these to any SHM that may exist. For example, it is reported that Tsing Ma and Stonecutters Bridges are extensively instrumented, and data collected. The GPS data on the Tsing Ma Bridge is used to detect bridge movements beyond normal ranges, which allows engineers to inspect and maintain the structure if required [Wong et al., 2001]. However, the full analysis of the data has not been reported, and it is not clear whether the frequencies of the movements are also analysed.

The issues associated with cost have been mentioned above; it is well-known that the use of GNSS is not cheap. Many researchers [Larocca et al., 2011; Cosser et al., 2004; Roberts et al., 2004b; Janssen and Rizos, 2005] have attempted to use cheaper single frequency systems along with signal processing to reduce costs, while others [Saeki, 2008; Saeki and Hori, 2006] have focused on signal processing alone. The cost of dual frequency receivers is now no longer the issue, although the use of good quality choke ring antennas to mitigate multipath errors is still strongly advisable. However, the authors believe that the cost of the GNSS equipment in relation to the cost of the bridge, or the value and benefit of extending the life of the bridge is small.

The following paper details GNSS surveying field work carried out on the M48 Severn Bridge, in March 2010, and gives a selection of results from the data and analysis. These results include the 
magnitude and frequencies of the movements of the various GNSS antennas attached to the cables, as well as those on the tops of the towers. The bridge is a $1,600 \mathrm{~m}$ long suspension bridge, with a main span length of $988 \mathrm{~m}$ long. This is thought to be the first time GNSS antennas have been attached to the suspension cables of such bridges to conduct this type of monitoring to this scale. The paper also illustrates the results under daily traffic and prevailing wind loading conditions.

\section{GNSS LOCATIONS AND METHODOLOGY}

The data gathering trials were conducted on two separate occasions, during the 10-12th March 2010 and again on 18th March 2010. During the surveys, the steel temperature varied from $2.5^{\circ} \mathrm{C}$ to $6^{\circ} \mathrm{C}$ on the $10^{\text {th }}, 1^{\circ} \mathrm{C}$ to $6^{\circ} \mathrm{C}$ on the $11^{\text {th }}, 3.5^{\circ} \mathrm{C}$ to $8.5^{\circ} \mathrm{C}$ on the $12^{\text {th }}$ and $8^{\circ} \mathrm{C}$ to $12.5^{\circ} \mathrm{C}$ on the $18^{\text {th }}$. The wind speed during these days varied up to $35 \mathrm{~m} / \mathrm{s}$ on the $18^{\text {th }}$ and up to $25 \mathrm{~m} / \mathrm{s}$ on the $10^{\text {th }}$ to $12^{\text {th }}$. Each session had the GNSS antennas located at 8 of the 9 survey points, along with 2 reference receivers. Figures 1 and 2 illustrate the locations of the GNSS antennas for the various sessions. The type of GNSS positioning used is known as kinematic GNSS, using on-the-fly carrier phase ambiguity resolution [Hofmann-Wellenhof et al., 2008; Roberts, 1997]. The carrier phase signal from these survey grade GNSS receivers have resolution in the order of sub-millimetre [Roberts $e t$ al., 2012; Roberts, 1997], and a potential resulting precision of a few millimetres. The technique relies on the GNSS receivers on the bridge being positioned relative to one or more reference GNSS receiver located on solid ground [Hofmann-Wellenhof et al., 2008]. The main reference GNSS receiver was located upon a survey point on top of the adjacent toll building, Figure 3 . A second backup reference GNSS receiver was placed on top of the temporary site office accommodation on the cliff compound. Both of these locations are on the land adjacent to the bridge, and within $2 \mathrm{~km}$ of the furthest GNSS antenna. The second static reference GNSS receiver will also be used to give an assessment of the accuracy and precision obtained in future research work.

\begin{tabular}{|c|c|c|c|c|c|c|c|}
\hline Location & 10.03 .10 AM & 10.03 .10 PM & 11.03 .10 AM & 11.03 .10 PM & 12.03 .10 AM & 12.03 .10 PM & 18.03 .10 \\
\hline A & 1200 & 1200 & 1200 & 1200 & 1200 & 1200 & SR510 \\
\hline B & 1200 & 1200 & 1200 & 1200 & 1200 & 1200 & 1200 \\
\hline C & 1200 & 1200 & 1200 & 1200 & 1200 & 1200 & 1200 \\
\hline D & 1200 & 1200 & 1200 & & 1200 & 1200 & 1200 \\
\hline E & & & & 1200 & & & 1200 \\
\hline T1 & SR530 & SR530 & SR530 & SR530 & SR530 & SR530 & SR530 \\
\hline T2 & SR530 & SR530 & SR530 & SR530 & SR530 & SR530 & SR530 \\
\hline T3 & SR530 & SR530 & SR530 & SR530 & SR530 & SR530 & SR530 \\
\hline T4 & SR530 & SR530 & SR530 & SR530 & SR530 & SR530 & SR530 \\
\hline
\end{tabular}

Figure 1. Session times, locations, dates and corresponding GNSS receiver types.

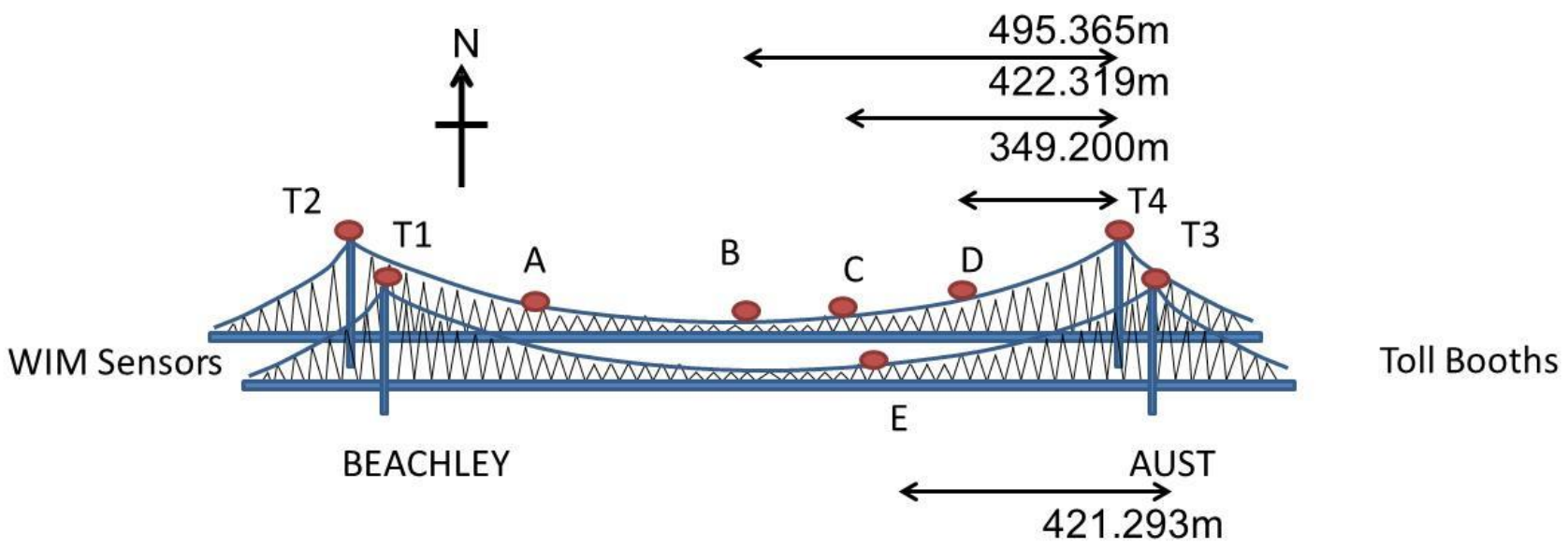


Figure 2. Survey points upon the bridge.

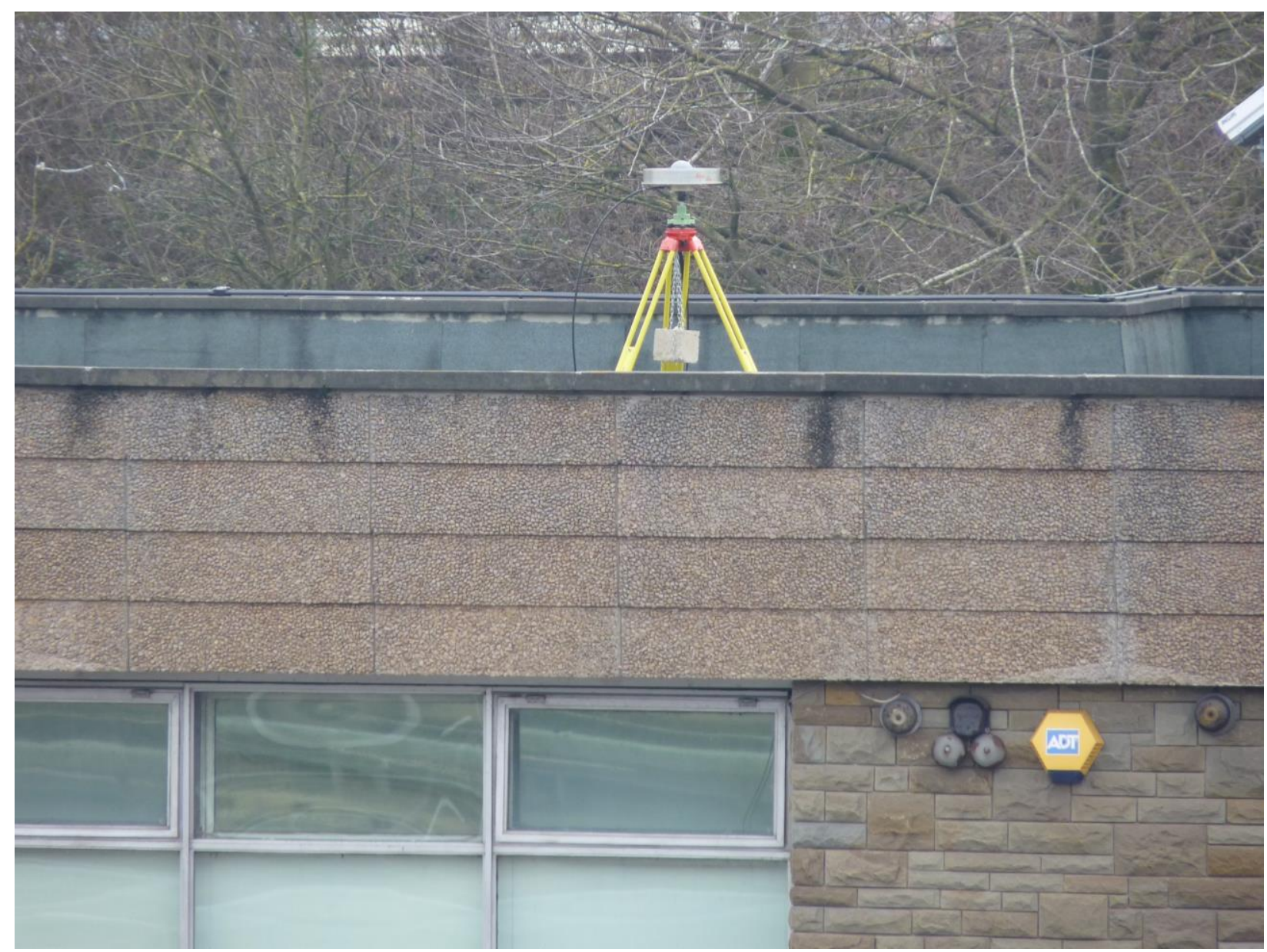

Figure 3. The principal reference GNSS antenna located upon an adjacent building to the bridge.

The survey points upon the bridge and cables were carefully attached by staff from Severn River Crossing Plc. (SRC), and the authors would like to take the opportunity to thank them for their kind efforts and care taken with the task. The GNSS receivers used were Leica 530 dual frequency geodetic GPS receivers, Leica 1200 dual frequency geodetic GNSS receivers, Leica SR510 single frequency geodetic GPS receivers and a Leica Viva GNSS receiver, and the antennas used were Leica choke ring antennas. The reason for the various types of GNSS receivers and antennas was mainly down to availability at the time. Previous work [Roberts et al., 2012] has shown an improved resolution for the 1200 receivers over the SR530, but they are still at the sub-mm level for the carrier phase observations. These comparisons were carried out through using zero baseline observations. The various sessions saw the antennas located at different survey points for some of the sessions. In particular, the focus for most of the survey was the upstream cable, where 4 antennas were placed (A, B, C, D). However, for a prescribed period, an antenna was placed on the downstream cable $\mathrm{E}$ - opposite position $\mathrm{C}$ (see Figures 1,2) to enable checks of the synchronous and differential nature of cable movement to be carried out. SRC attached the 4 choke ring antennas to the very top of the towers, Figure 4, and carefully trailed the $50 \mathrm{~m}$ antenna cables into the enclosed crossway. This meant that it was a safer and sheltered environment for the authors to be able to download the data, under the supervision of SRC staff. It also meant that an uninterrupted mains power supply was available. In addition to this, SRC attached the antennas directly to the suspension cables, Figure 5, and 50m cables were carefully placed so that the authors could attach the GNSS receivers to the cables at bridge deck level. This allowed easy battery changeover as well 
as data downloading. Data was downloaded on a periodic basis in order to prevent large data loss in case of any issues with the receiver. In this case there were none.

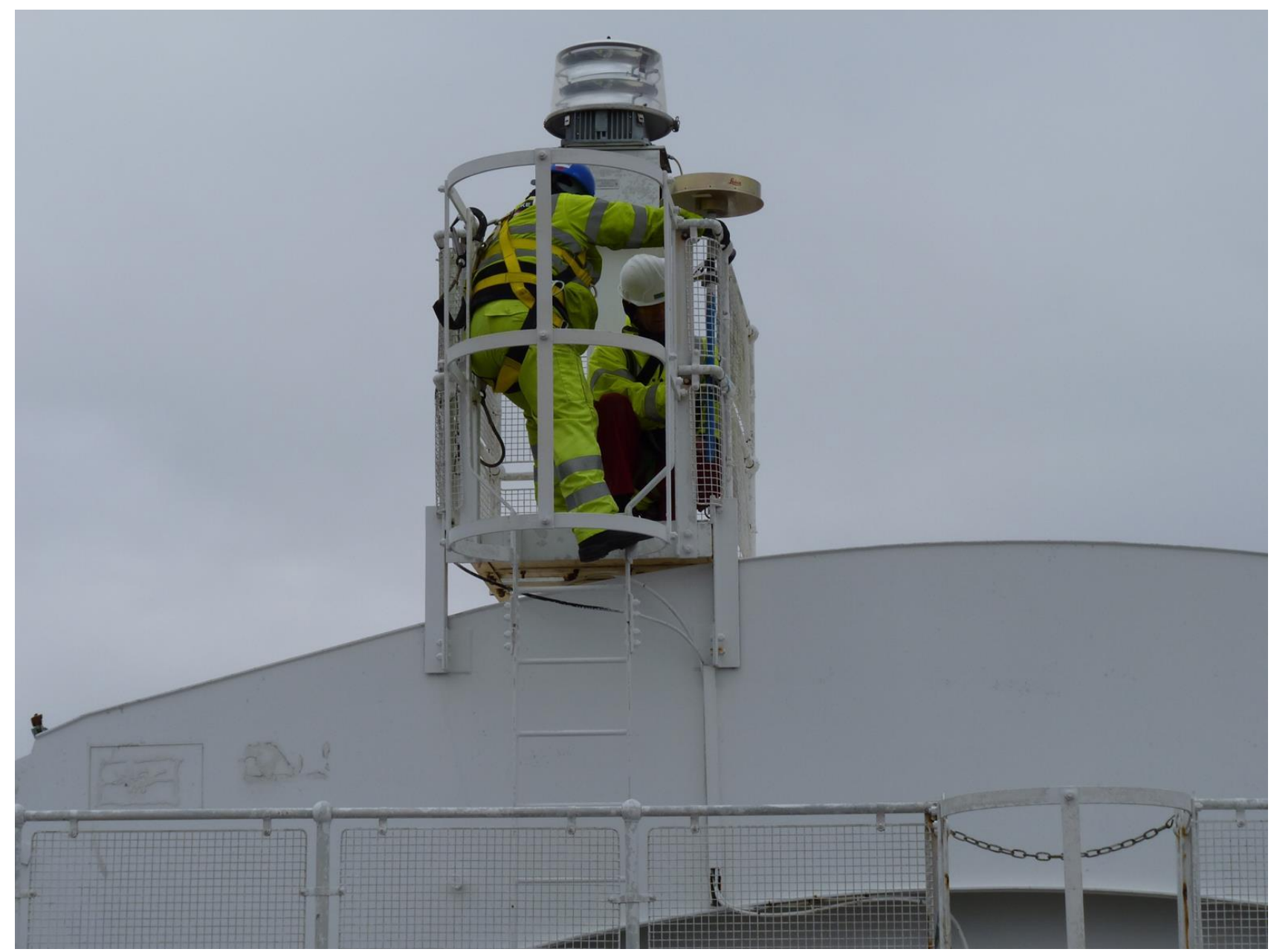

Figure 4. The GNSS antennas located at survey point T2 on the bridge. The illustration shows the GNSS antenna being installed

The raw GNSS data were gathered at a rate of $20 \mathrm{~Hz}$ for the 1200 and Viva receivers, and $10 \mathrm{~Hz}$ for the SR510 and SR530 receivers. Due to the high resolution of the GNSS carrier phase data used, in addition to using the choke ring antennas, the precision of the results were expected to be at the millimetre level. Previous work has demonstrated that the resolution of the carrier phase for both the 1200 and SR530 GPS receivers lies at the sub-mm level [Roberts et al., 2012]. Great care was taken in choosing the location of the antennas, as well as using choke ring antennas at as many of the locations as possible; all in order to reduce the multipath effect. Once gathered, the GNSS data were post processed through a technique known as On-The-Fly (OTF) kinematic processing, resulting in data files that consist of 3D coordinates in WGS84 coordinate system with corresponding times at either 0.05 or 0.1 second intervals. Due to the large data files, the sessions were split for processing purposes. Subsequently the resulting coordinates were transformed into the bridge coordinates, and the results illustrated in this paper are based on these. The orientation of the bridge was calculated through using the known average coordinates of the cable GNSS receivers, and calculating the bearing between them which resulted as a bearing of $120^{\circ}$. The movements are referred to as longitudinal movements, lateral movements and vertical movements, all referring to the direction relative to the bridge's axis.

It is not possible to calculate directly the exact accuracy of the GNSS solution with the configuration of receivers and antennas used for this test. It is possible to calculate the precision, 
which will be shown to be in the order of a couple of millimetres. The Bridge's GNSS data is processed relative to the local reference GNSS receiver's data, and this type of processing will eliminate most of the error due to the satellite signals travelling through the ionosphere and troposphere, as well as satellite based errors. Any local multipath noise will be vastly reduced as choke ring antennas were used and located as carefully as possible not to be too close to the bridge's infrastructure in order to reduce multipath reflection during these surveys [Hofmann-Wellenhof $e t$ al., 2003, 2008]. The moving nature of the GNSS satellites mean that the location of these at any instant will vary, and satellite constellation geometry induced errors will exist. The authors did have a second GNSS receiver located nearby, and this could be used to assess the quality of the GNSS solution on the bridge locations. This can be done by computing the the apparent movements of the second stationary GNSS receiver relative to the first, and as long as the same satellites as being used for the positional solution, then any apparent movement is due to the geometrical location of the satellites used, and hence the same as those on the bridge at that instance. This is all assuming that the multipath error is mitigated using the choke ring antennas. However, the multipath errors can also be assessed through comparing subsequent days of results, as the satellite constellation repeats itself every 11 hours and 56 minutes, hence the multipath will be the same four minutes earlier every day. This is all the scope of current research, and is focussing on the GNSS algorithms and output, rather than this paper which is focussed on the actual movements and what this could mean to bridge owners. Figure 5 illustrates one of the choke ring antennas located on the cable. This is, as far as the authors can deduce, the first time that such an elaborate measurement of this type has been carried out, on both the towers and various locations on the cables at the same time. The results are direct movements of the suspension cable. The research also investigated the relationship between the movements detected on the cables with those of the towers. This will be the focus of a future paper. 


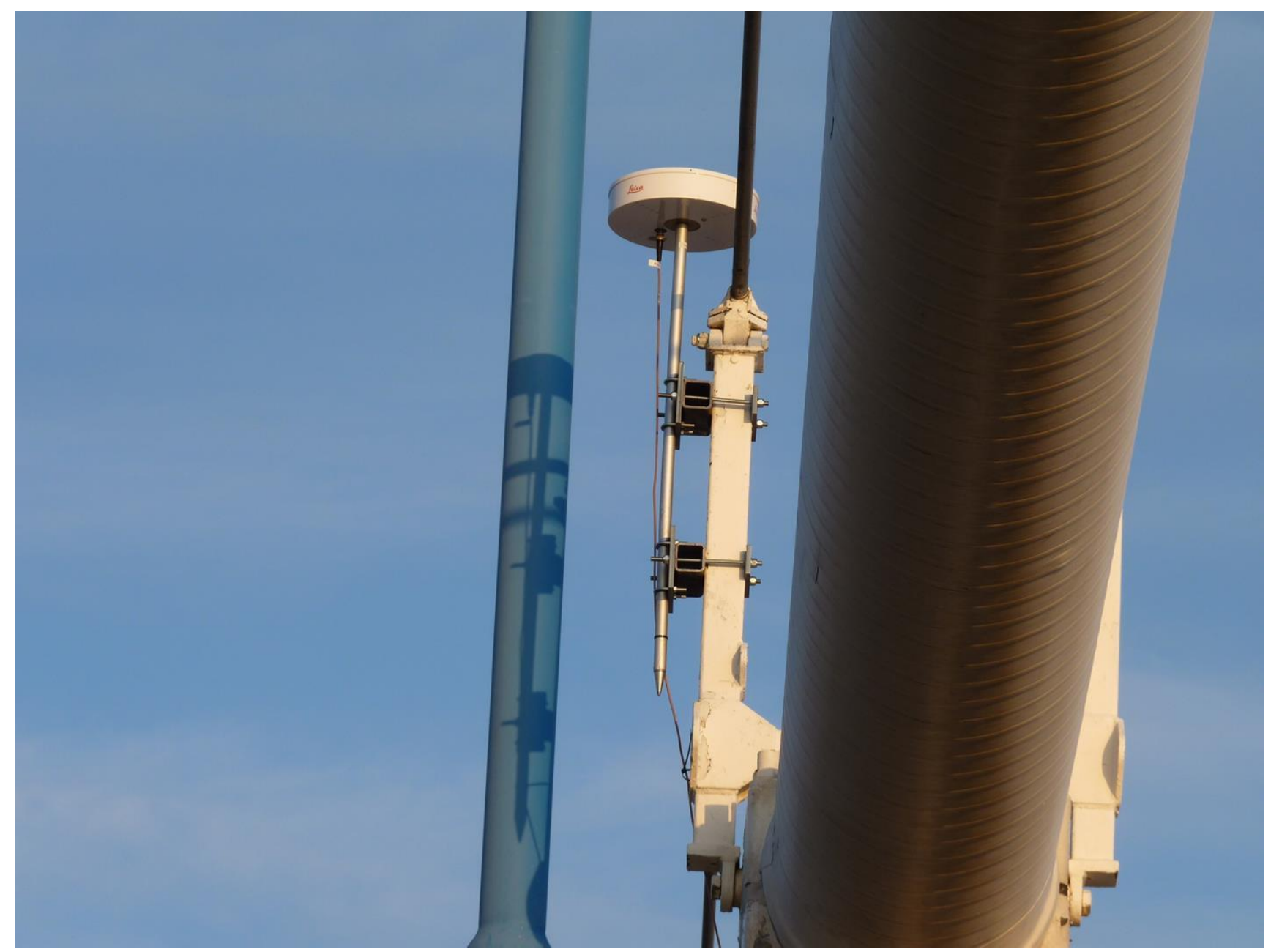

Figure 5. GNSS choke ring antenna located on the suspension cable.

\section{RESULTS}

\subsection{Bridge Cable Movement Results}

Due to the vast amount of data gathered, the results and number of data-points are phenomenal. 36,000 3-dimensional data points are gathered every hour by each of the $10 \mathrm{~Hz}$ GNSS receivers, twice this for the $20 \mathrm{~Hz}$ receivers. This would result in just under 7 million 3-dimensional data points for all the 8 GNSS receivers upon the bridge, if gathering data at $10 \mathrm{~Hz}$ over a 24 hour period. This section illustrates a small subset of the results, and various processing techniques have been used.

Figure 6 illustrates the 3D movements in bridge coordinates of the GNSS antenna located at point B, over approximately a 4 hour period of time. The deflections in the vertical direction can be seen to reach over $0.4 \mathrm{~m}$ in magnitude at times. All these deflections are predominately due to the mass of traffic travelling over the structure. In addition to the vertical movements, the lateral deflections show a relationship with some of the vertical. It is also visible from the diagram that the height of the bridge gradually changes over time. This is thought to be due to the heating effect during the day causing the cables to expand and hence causing them to sag. This has also been evident on the Humber Bridge [Roberts et al., 2010]. 


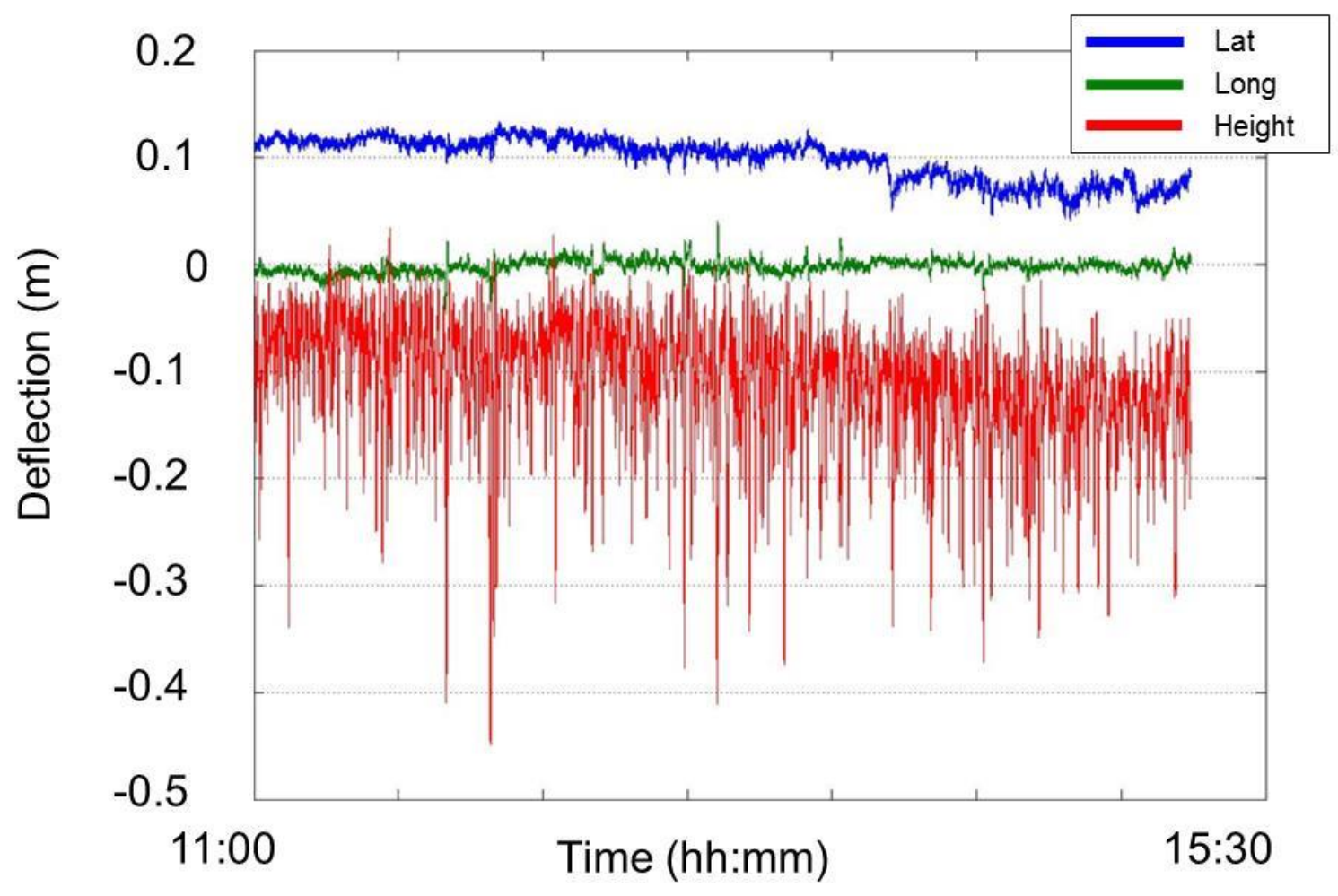

Figure 6. Deflections at point B from 11:00 to 15:30.

Figures 7 and 8 illustrate smaller periods of time, 10 minutes and 1 minute respectively. From these figures, and in particular Figure 8, the cyclical nature of the vertical deflections is evident. Further to this, the noise of the GNSS results can be seen in these figures in particular in the lateral and longitudinal components of Figure 8. Here it can be seen that there is a precision of the order of a few millimetres. Similarly in the height component, if the cyclic movements were ignored, the resulting noise can be seen to be at the millimetre level. The values for the noise have not been quantified as yet, but the noise and actual vertical movements are clearly distinguishable from each other in the figures. 


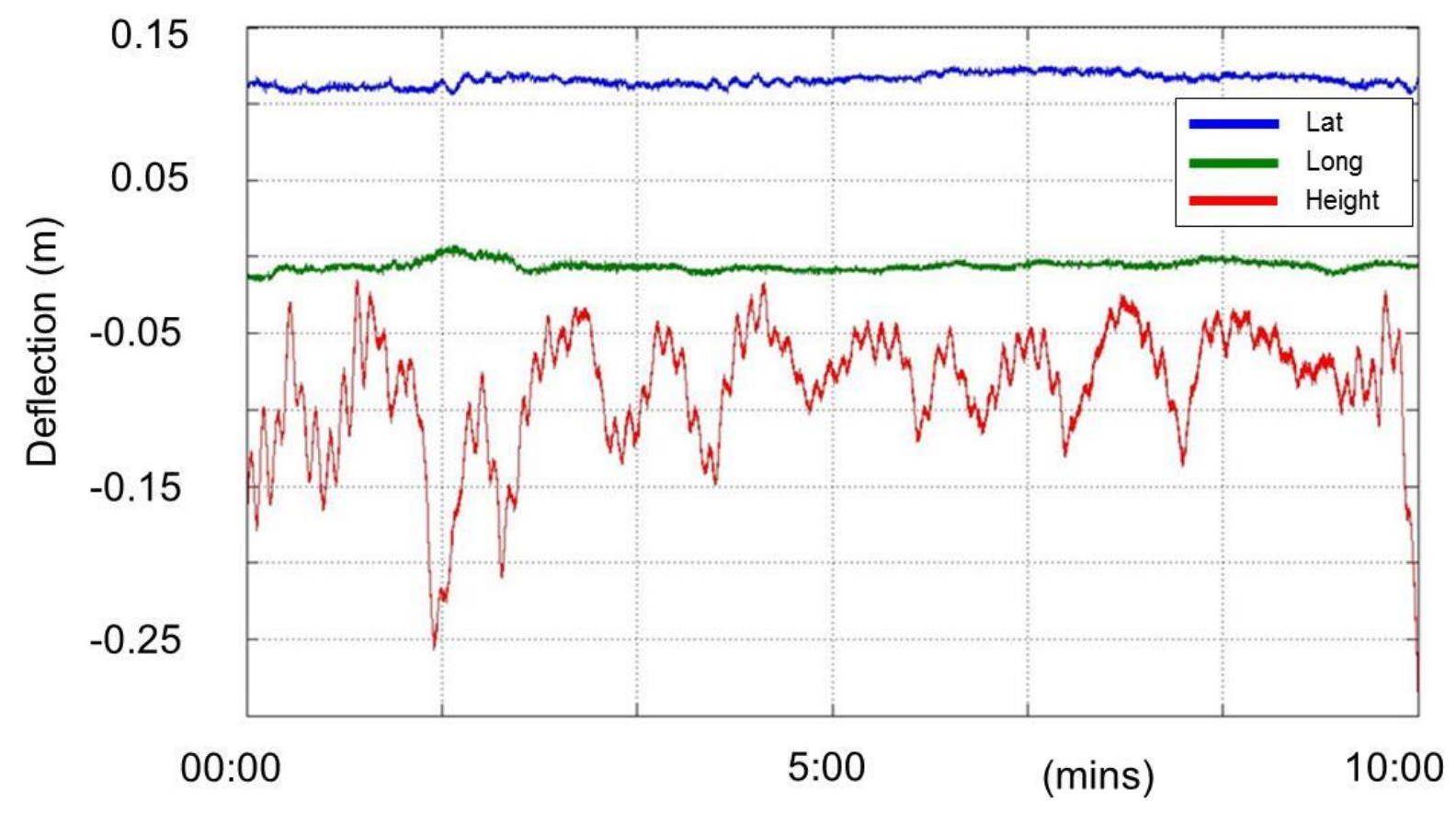

Figure 7. Deflections at point B over a 10 minute period.

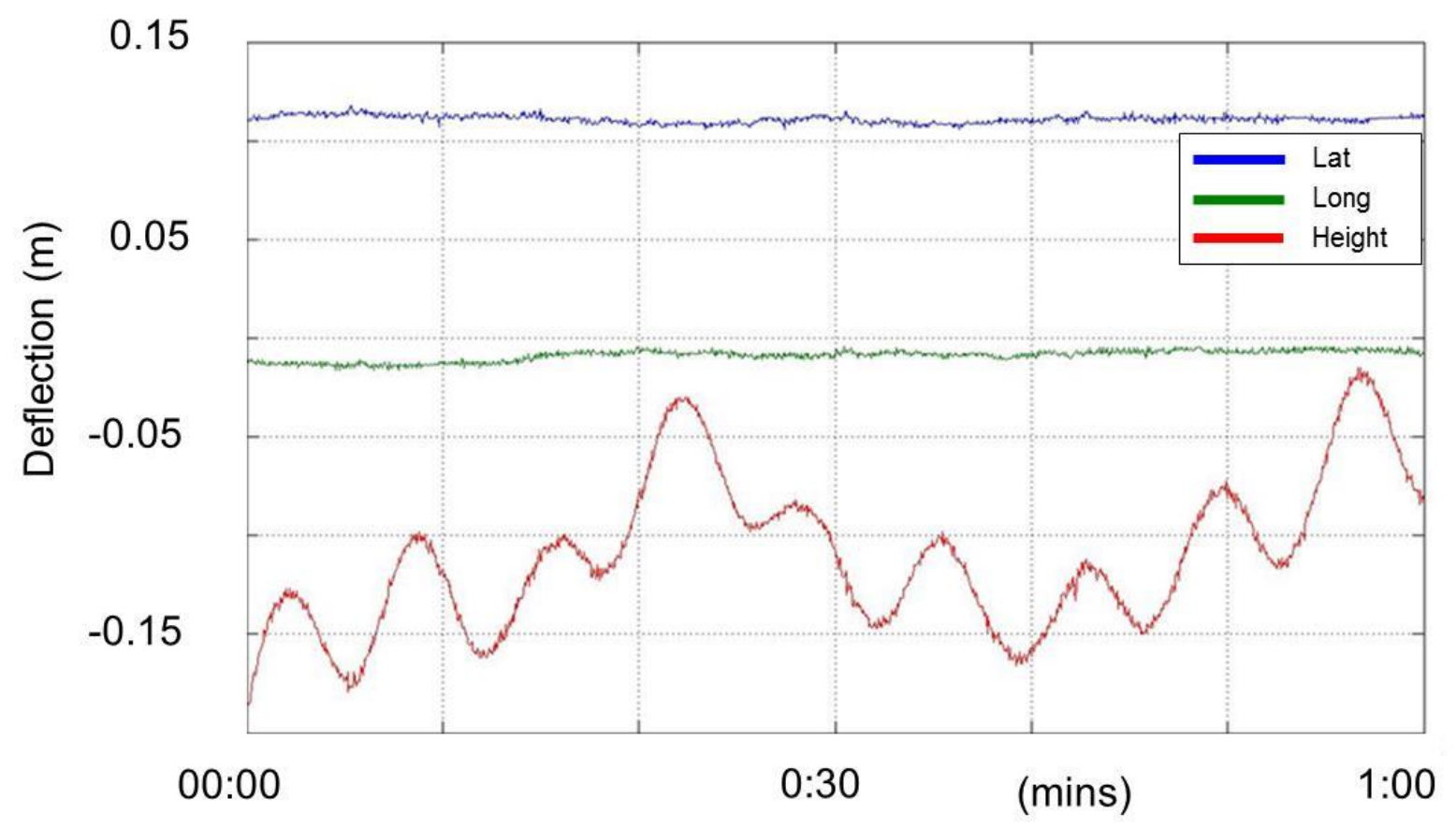

Figure 8. Deflections at point B over a 1 minute period.

GNSS data at both locations $\mathrm{C}$ and $\mathrm{E}$ were gathered during certain periods. This means that the torsional or "galloping" movements of the bridge can be extracted. Figure 9 illustrates the lateral, longitudinal and height movements of location $\mathrm{C}$ and location $\mathrm{E}$ over a 30 minute period. In addition, the differences between $\mathrm{C}$-E are also illustrated in the three axes. It can be seen that there is little short term relative movements in the horizontal components, and the majority of the differential movements are in the height component, with relative peak to peak movements of up to $96.3 \mathrm{~mm}$ in the height component. Similarly, peak to peak movements in the height component in Figure 10 are seen of up to $116.2 \mathrm{~mm}$. 


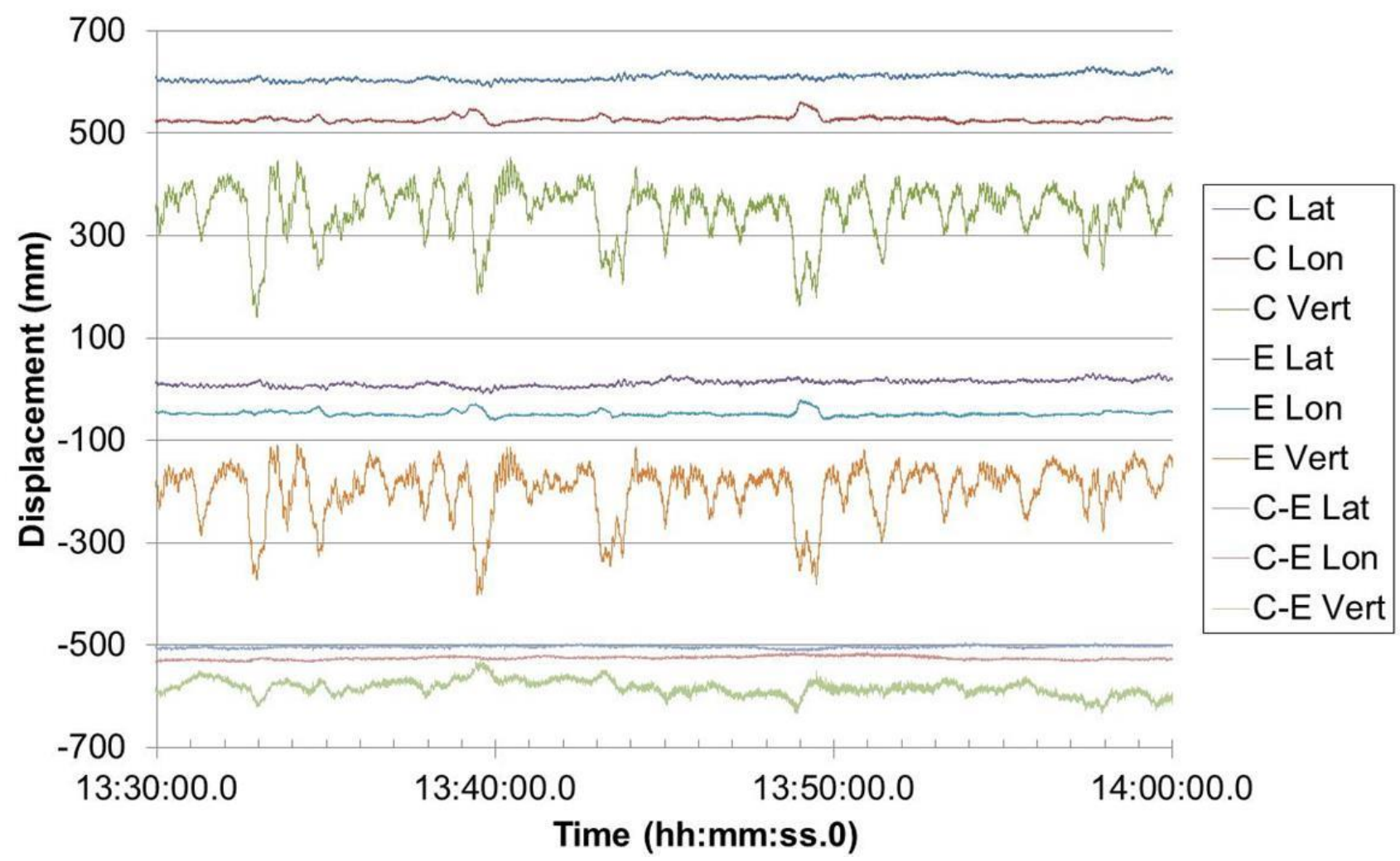

Figure 9. Lateral, longitudinal and height deflections at locations $\mathrm{C}$ and $\mathrm{E}$, as well as the differential movements C-E. This illustrates the torsional movements during this period.

Figure 10 illustrates the differential movements between locations $\mathrm{C}$ and $\mathrm{E}(\mathrm{C}-\mathrm{E})$ over a 30 minute period. This figure is used to try and illustrate the precisions obtained from the GNSS derived results. The accuracy and precision of the GNSS derived solution will vary when using kinematic GNSS. Most of the ionospheric and tropospheric errors will be eliminated through the relative positioning of the bridge's GNSS receivers relative to the reference station. The satellite clock errors and satellite positional errors will also be eliminated through relative positioning. Any multipath errors will be vastly reduced through the careful location of the antennas in addition to using choke ring antennas [Hofmann-Wellenhof et al., 2003, 2008]. The remaining error sources are due to the geometry of the satellite constellation constantly changing as well as the receiver noise. Partly due to all the satellites being above the user, the height component is always worse in accuracy and precision than the plan component. Similarly, due to the nature of the satellite constellation, there will never be a GPS satellite seen in the north direction in the UK. They will always be to the east, west and south of the user. This will result in a north-south geometry inbalance, and hence more noise resulting in less precision and accuracy in this direction [Roberts et $a l ., 2006]$. Figure 10 illustrates the differential movements between locations $C$ and $E$. There are obviously differential movements between these locations; however, the horizontal component is very small. The C-E result will include some relative movements as well as the noise within the two individual locations' positional solution due to both the receiver noise as well as the geometry induced noise. Saying all this, it can be seen that the difference in lateral and longitudinal differential movements is of the order of millimetres, and the Root Mean Square of these scatters are $2.5 \mathrm{~mm}$ and $2.8 \mathrm{~mm}$ respectively. This gives an indication of the precision. In reality, the positional solution of each individual location will have a precision better than this. Work is ongoing to look at the GNSS characteristics of these results, through carrying out similar analysis during calm periods where there is little traffic and wind loading on the bridge, as well as 
positioning between the two static reference GNSS receivers in order to assess the noise in the positional solution.

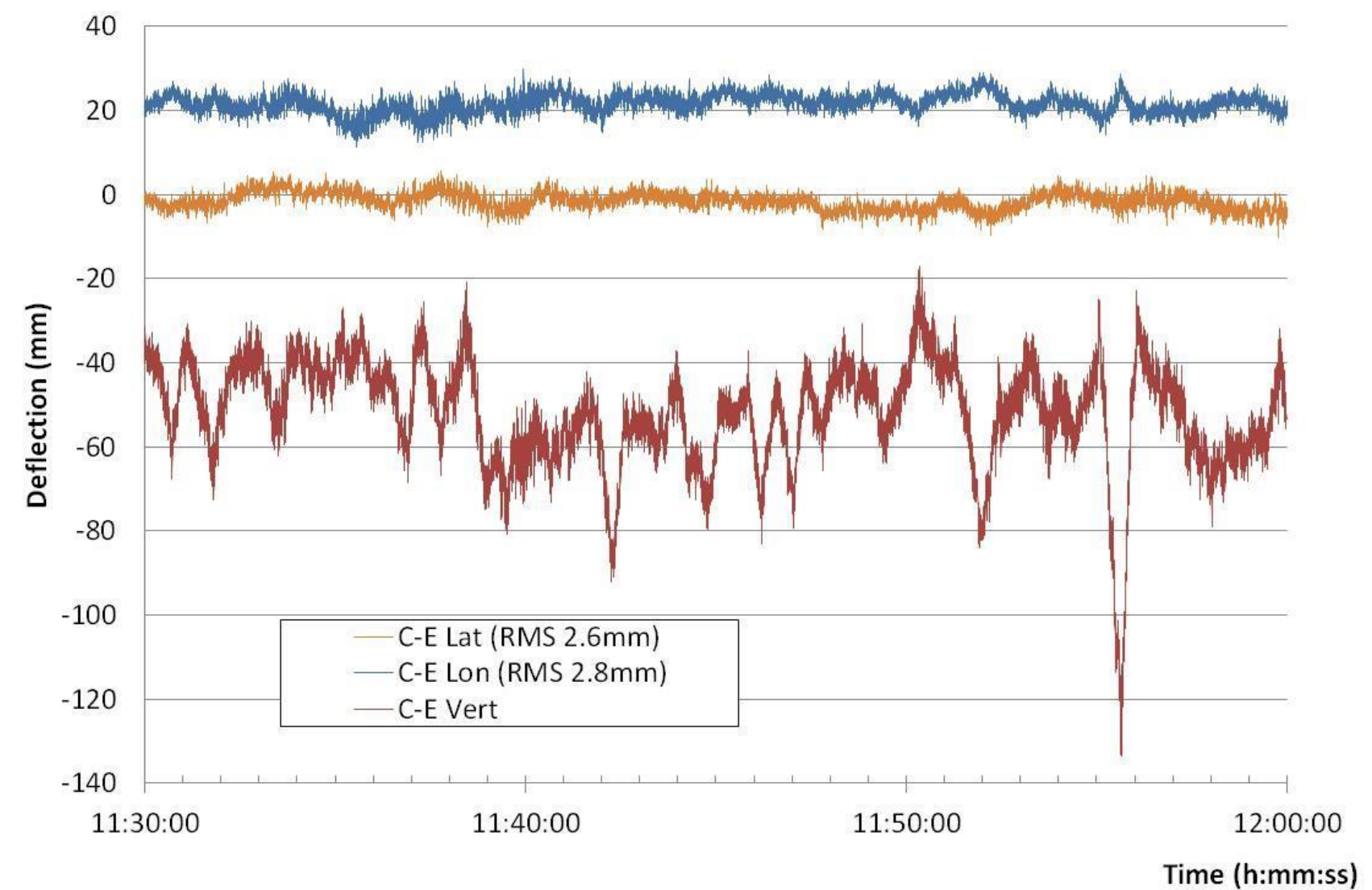

Figure 10. Lateral, longitudinal and vertical differential movements between locations C-E. This figure helps to illustrate the precision of the GNSS noise, illustrating the RMS of the lateral and longitudinal differential movements.

\subsection{Bridge Cable Frequency Results}

Frequency response analysis was carried out on the data. Figure 11 illustrates the results for point B. It is clear that at least two vertical frequencies are present in this data at about $0.146 \mathrm{~Hz}$ and 0.2265 Hz. Further analysis of the results is currently being conducted, in particular to assess how these frequencies vary due to changing external factors such as the temperature and mass of traffic loading. [Brown et al., 2007]. 


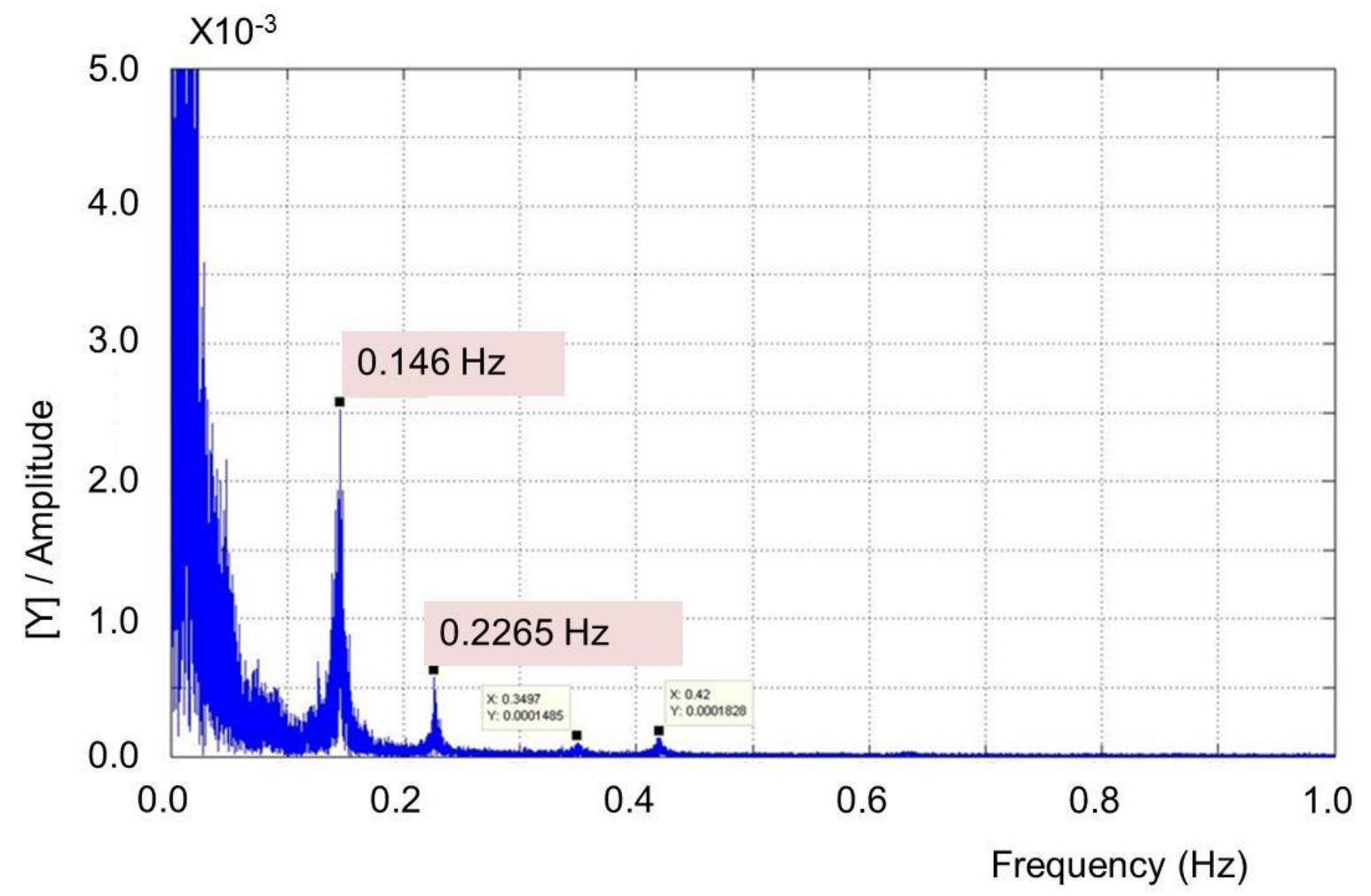

Figure 11. Frequency response in the vertical direction at point B.

Figures 12 and 13 illustrate the height deflections of all 4 locations on the bridge over a 40 minute and 10 minute period, respectively. It is evident from figure 13 in particular that some of the deflections are slightly offset from each other. This is due to the mass of the vehicles travelling over the bridge. Due to the varying nature of traffic movements over the bridge, from both directions and over all the lanes, the movements are also variable in nature. Figure 13, for example, shows a lot of movement in particular just after 13:15, but then shows little movement at approximately 13:17 to 13:19; apart from the cyclical movement of the bridge. 


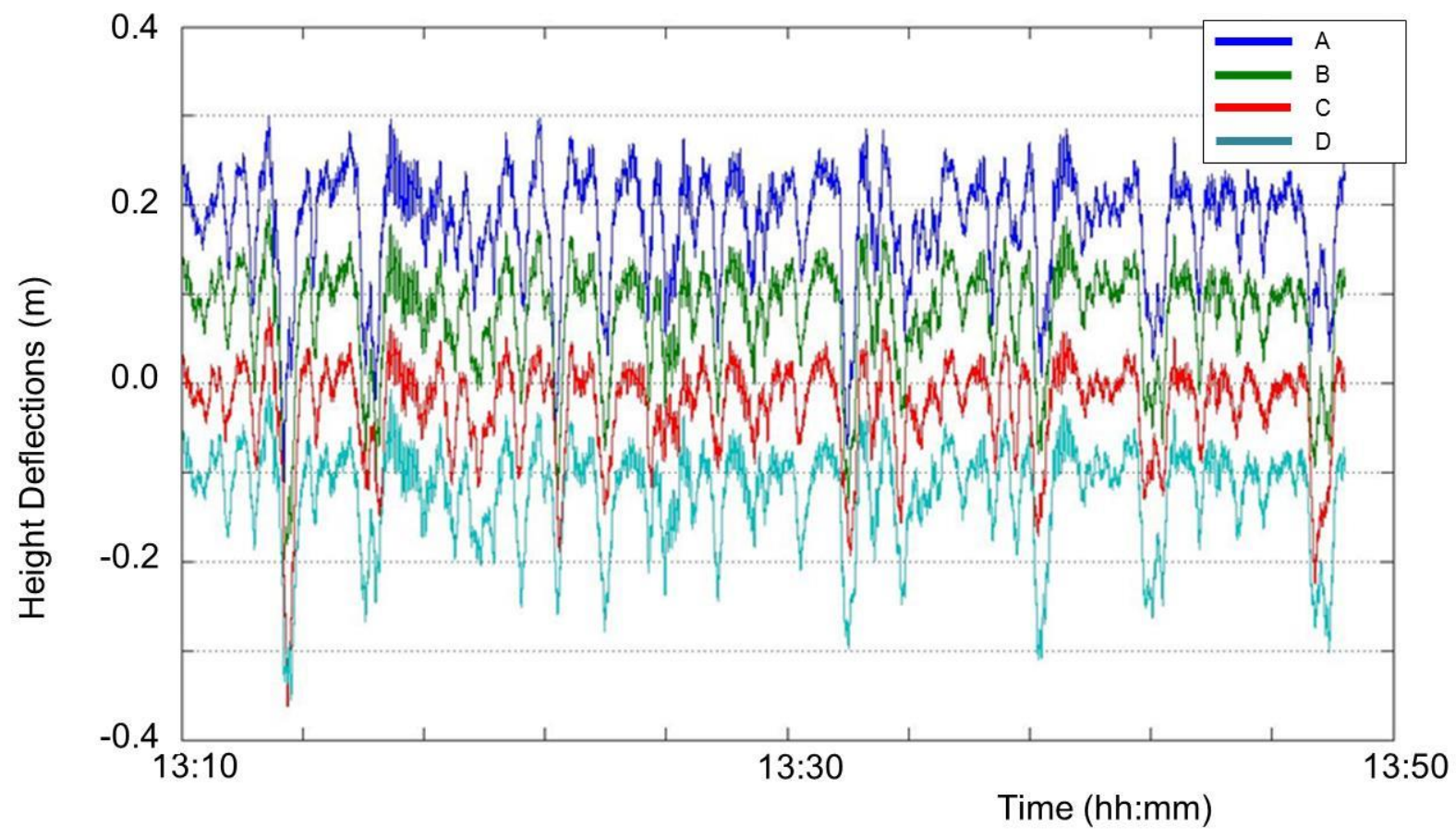

Figure 12. Vertical Deflections for 4 locations over a 40 minute period.

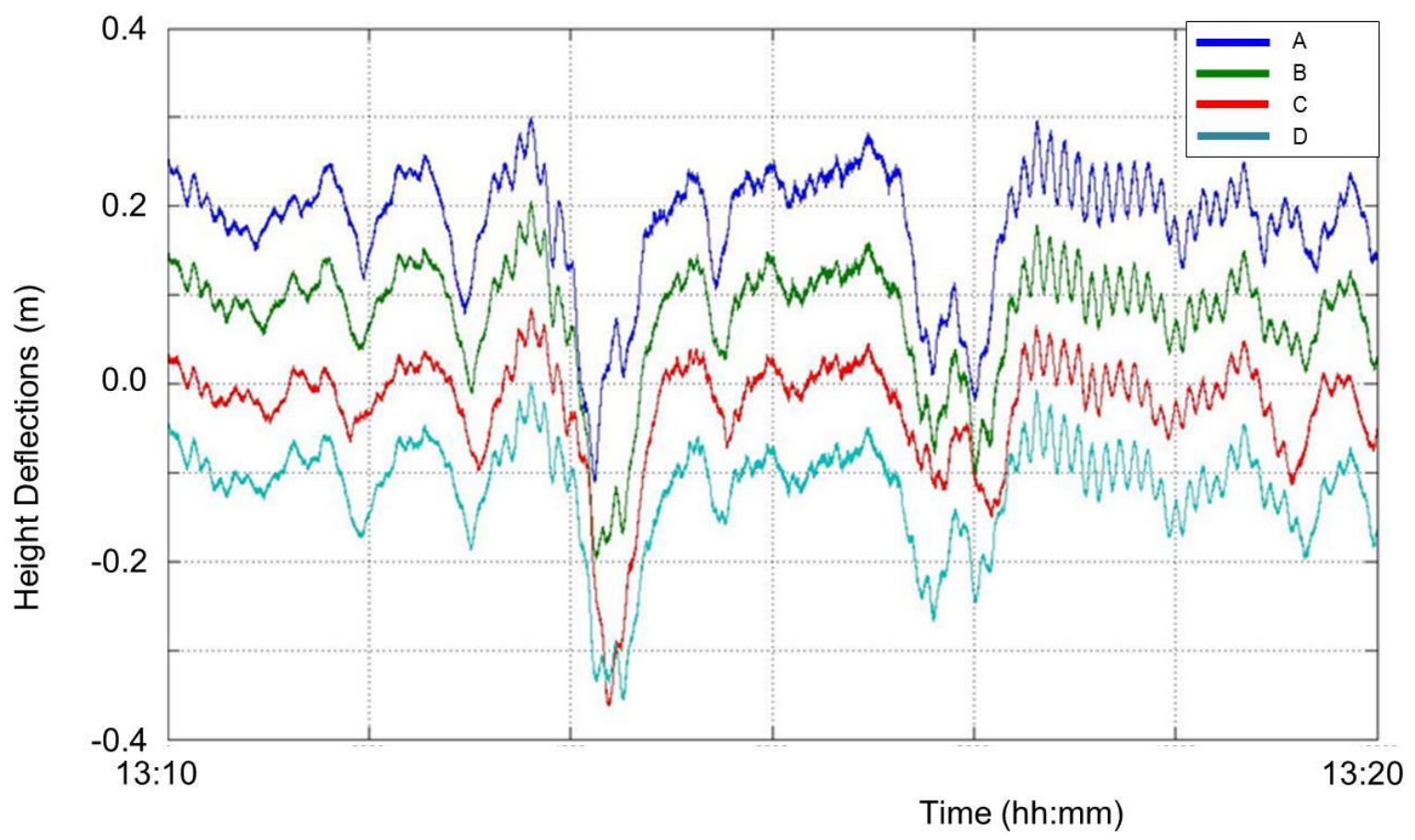

Figure 13. Vertical Deflections for 4 locations over a 10 minute period.

\subsection{Bridge Tower Results}

Figure 14 illustrates the longitudinal movements of all 4 locations on top of the towers over a 10 minute period. It can be seen that the movements are up to 2 or $3 \mathrm{~cm}$ in magnitude, and at times the 4 locations move in synchronous motions. This can be seen, for example, at about the 1 minute 
mark and the 9 minute mark. The synchronous aspects of these movements is currently being researched in further detail.

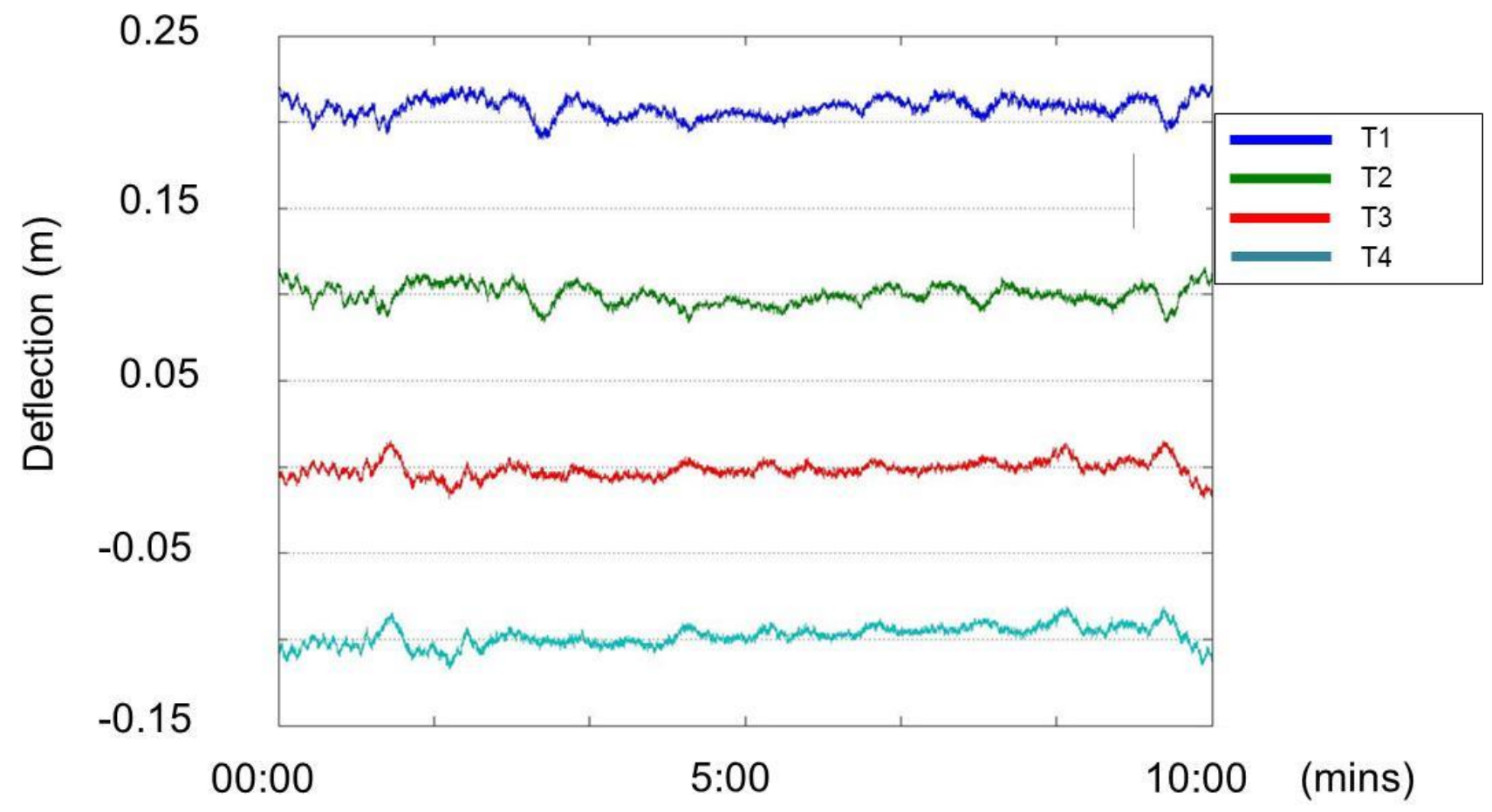

Figure 14, Longitudinal movements of the 4 Tower tops over a 10 minute period.

Figure 15illustrates the tower longitudinal movements' frequencies obtained by carrying out a Fast Fourier Analysis on the relevant GNSS data. Here it can be seen that the main natural frequency of the Bridge is seen in the tower movements, at around $0.146 \mathrm{~Hz}$, at all four locations.
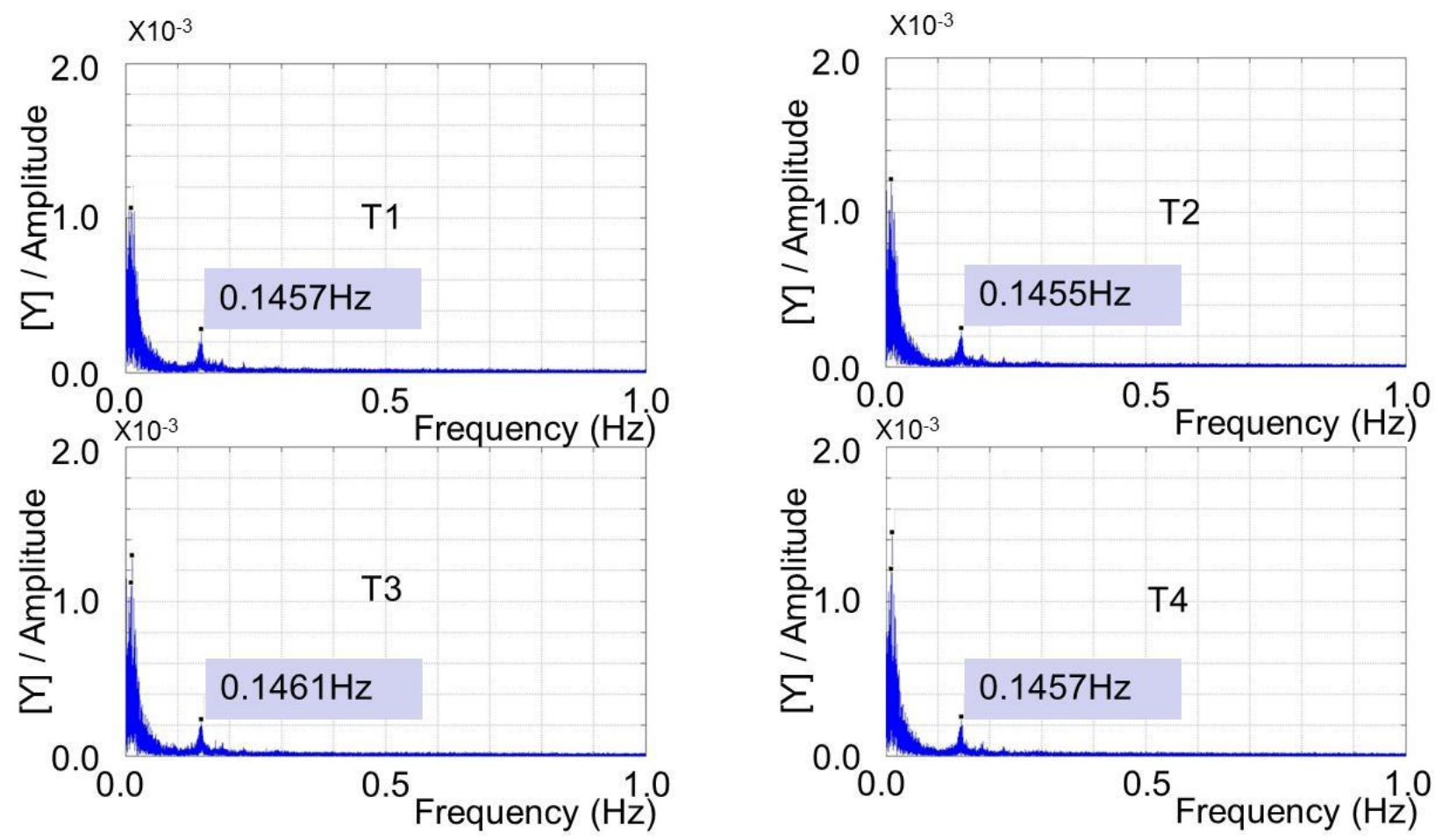
Figure 16 illustrates the average frequencies at all the locations upon the bridge. It can be seen that there are common frequencies throughout the various locations, and in particular that there is the main natural frequency of the bridge of approximately $0.146 \mathrm{~Hz}$ at measured at all the locations. This is not only for the cable locations, but also the tower locations (T1-4), and illustrates that the main frequency of the structure can be measured at a number of different locations simultaneously.

\begin{tabular}{|c|c|c|c|c|c|c|c|c|c|}
\hline \multirow[b]{3}{*}{ Position } & \multicolumn{5}{|c|}{ vertical } & \multicolumn{4}{|c|}{ Iongitudinal } \\
\hline & \multicolumn{5}{|l|}{$\Gamma$} & \multicolumn{4}{|l|}{ r } \\
\hline & A & B & C & D & $E$ & T1 & T2 & T3 & T4 \\
\hline Freq & 0.0595 & & & & & & & & \\
\hline \multirow[t]{3}{*}{$\mathrm{Hz}$} & 0.1453 & 0.146 & 0.1448 & 0.1457 & 0.1457 & 0.1457 & 0.1455 & 0.1461 & 0.1457 \\
\hline & 0.1862 & & 0.1847 & 0.1847 & & & & & \\
\hline & & 0.2265 & 0.2264 & & 0.2264 & & & & \\
\hline
\end{tabular}

Figure 16, Natural Frequencies derived from the GNSS results at the various locations.

\section{CONCLUSIONS}

GNSS can be permanently attached to a structure, or temporarily attached. The hypothesis of using GNSS for long term monitoring of the magnitude and frequencies of the bridge movements is that over time, these characteristics will change, as the bridge deteriorates. In reality, only periodic measurements are required in order to investigate these gradual changes. However, the advantage of having the GNSS antennas and receivers permanently attached is that they will capture movements due to exceptional events. Such events could be traffic loading, or extreme weather causing large wind loading. Some of the extreme traffic loading can be planned. The authors were able to gather data on the Humber Bridge and also the Forth Bridge when large vehicles passed over [Brown et al., 1999; Roberts et al., 2012] but exceptional weather occurrences are not always planned. Wong et al. [2001] also planned to gather data on the Tsing Ma Bridge during Typhoon conditions.

This paper has shown that GPS monitoring is becoming increasingly viable, particularly on critical parts of infrastructure, to establish and maintain data on the condition of a significant range of structures. Such GNSS data could be used by bridge owners to help establish a realistic SHM of a bridge, through using real data in the model.

The data also documents the results obtained from the Severn Bridge during typical traffic and wind loading. This data allows a base set of data or a blueprint of the Bridge's movements to be obtained and recorded. This can be compared to in the future with compatible data in order to assess any changes in such movements over time. Again, this could be incorporated using a SHM, and comparing the real data with this. Any anomalies in the results, due to deterioration, could possibly be tackled through refurbishing the bridge, thus increasing its lifespan.

The results from this piece of field work are under continuing analysis. The synchronous nature of the results, as well as their relationship to the weigh in motion data is being analysed. 


\section{ACKNOWLEDGEMENTS}

The authors are very grateful to the Highways Agency, Severn River Crossing Plc, and Mott MacDonald for supporting and funding this research, and for helping and allowing the extensive field work to be carried out, resulting in a very in depth study of the movements. Very special thanks go to the staff at the Severn Bridge who were extremely helpful to us, in particular in attaching the GNSS antennas to the structure during some very cold weather.

\section{REFERENCES}

Ashkenazi, V; Dodson, A H; Moore, T; Roberts, G W; (1996) Real Time OTF GPS Monitoring of the Humber Bridge, Surveying World, Vol. 4, Issue 4, ISSN 0927-7900, pp 26-28.

Ashkenazi V. and Roberts G. W., (1997) Experimental Monitoring the Humber Bridge with GPS. Proc. Instn Civ. Engrs, Civ. Engng, vol 120, Issue 4., pp. 177-182. ISSN 0965089 X.

Brown, C J; Karuna, R; Ashkenazi, V; Roberts, G W; Evans, R; (1999) Monitoring of Structures using GPS, Proc Institution of Civil Engineers, Structures, ISSN 0965 092X, pp 97 - 105.

Brown, C. J.; Roberts, G. W.; Atkin, C.; Meng, X.; Colford, B. (2007) Deflections and Frequency Responses of the Forth Road Bridge Measure by GPS. In "Fifth international Conference on Current and Future Trends in Bridge Design, Construction and Maintenance". Edited by R Lark. Thomas Telford Publishing. pp 479 - 486. ISBN 978-07277-3593-5.

Cosser, E.; Roberts, G. W.; Meng, X.; and Dodson, A. H.; (2004). Single Frequency GPS for Bridge Deflection Monitoring: Progress and Results. First FIG International Symposium on Engineering Surveys for Construction Works and Structural Engineering, Nottingham, UK.

Hofmann-Wellenhof, B.; Lichtenegger, H.; Wasle, E.; (2003) Navigation, Principles of positioning and guidance. SpringerWien New York. ISBN 978-3-211-00828-4.

Hofmann-Wellenhof, B.; Lichtenegger, H.; Wasle, E.; (2008) GNSS Global Navigation Satellite Systems. SpringerWien New York. ISBN 978-3-211-73012-6.

Janssen, V.; Rizos, C.; (2005) Mixed-mode GPS deformation monitoring - A cost-effective and accurate alternative? In A Window on the Future of Geodesy. International Association of Geodesy Symposium, Springer Berlin Heidelberg. Volume 128, pp 522-527, editor Prof E Sanso. DOI: 10.1007/3-540-27432-4_90. Print ISBN 978-3-540-24055-6. Online ISBN 978-3-540-27432-2.

Jiang, J.; Lu, J.; Guo, J.; (2002) Study for Real-time Moniotoring of Large-span Bridge Using GPS. Proc. ISSST 2002, "Progress in Safety Science and Technology", Beijing/New York: Science Press, eds. Huang, P.; Wang, Y. J.; Li, C. C.; Qian, X. M. ISBN 7-03-010787-X/X*72, Vol. 3, 308 312, Tai'an. 
Larocca, A. P. C.; Schaal, R. E.; Santos, M. C.; (2011) The use of L1 GPS Signal as a tool for Monitoring Structural Oscillations of Bridges - A Compendium about the Phase Residual Method Applications. Proc Joint International Symposium on Deformation Monitoring (JISDM), Hong Kong.

Liu, H.; (2013) Structure Deformation Test in Extra Long-Span Bridge Load Test. Proc 2nd Joint International Symposium on Deformation Monitoring (JISDM), Nottingham.

Meo, M.; Zumpano, G.; Meng, X.; Roberts, G. W.; Cosser, E.; and Dodson, A. H.; (2004) Identification of Nottingham Wilford Bridge Modal Parameters Using Wavelet Transforms. In: peer-refereed Proc of SPIE, Smart Structures and Materials 2004: Modeling, Signal Processing, and Control, Ralph C. Smith, Editor, July 2004, Vol. 5383: 561-570.

Ogaja, C.; Wang, J. L.; Rizos, C.; Brownjohn, J. M. W.; (2002) Multivariate monitoring with GPS. Observations and auxiliary multi-sensor data, GPS Solutions Volume 5, Issue 4, pp 58-69.

Ogundipe, O.; Roberts, G. W.; Brown, C. J.; (2012) GPS monitoring of a steel box girder viaduct. Structure and Infrastructure Engineering: Maintenance, Management, Life-Cycle Design and Performance. DOI:10.1080/15732479.2012.692387. ISSN 1573-2479 print/ISSN 1744-8980 online.

Rizos, C.; Han, S.; (1998). Precise kinematic applications of GPS: prospects and challenges. Boletim Ci. Geodesicas, Curitibo, Brazil, 3, 3-33.

Roberts, G. W.; (1997) Real Time On-The-Fly Kinematic GPS. PhD thesis, The University of Nottingham. etheses.nottingham.ac.uk/3395.

Roberts, G. W.; Meng, X.; Dodson. A. H; (2000) Structural Dynamic and Deflection Monitoring Using Integrated GPS and Triaxial Accelerometers, Proc ION-GPS-00, The 13th International Technical Meeting of the Satellite Division of the Institute of Navigation, Salt Lake City, USA.

Roberts, G W; Meng, X; Dodson, A H; (2004a) Integrating a Global Positioning System and Accelerometers to Monitor the Deflection of Bridges. Journal of Surveying Engineering, American Society of Civil Engineers, Volume 130, No 2, pp 65 - 72, ISSN 0733-9453.

Roberts, G. W.; Meng, X.; Cosser, E.; Dodson, A. H.; (2004b) The Use of Single Frequency GPS to Measure the Deformations and Deflections of Structures. Proceedings of the FIG Working Week, Athens.

Roberts, G. W.; Meng, X.; Brown, C. J.; Dallard, P.; (2006) GPS measurements on the London Millennium Bridge. PROCEEDINGS- INSTITUTION OF CIVIL ENGINEERS BRIDGE ENGINEERING, 159(4), pp 153-162.

Roberts, G. W.; Brown, C. J.; Ogundipe, O.; (2010) Monitoring Bridges by GNSS. Proc FIG Congress "Facing the Challenges - Building the Capacity", Sydney, Australia.

Roberts, G. W.; Brown, C. J.; Meng, X.; Ogundipe, O.; Atkins, C.; Colford, B.; (2012) Deflection and Frequency monitoring of the Forth Road Bridge, Scotland, by GPS. ICE Proceedings; Bridge Engineering. ISSN: 1478-4637, E-ISSN: 1751-7664, Volume 165, Issue BE2, pp 105 - 123. 
Saeki M., (2008) Development of affordable GPS displacement monitoring system; in Bridge Maintenance, Safety Management, Health Monitoring and Informatics: Proceedings of the Fourth International Conference on Bridge Maintenance- IABMAS '08, Koh and Frangopol (Eds) July 13-17 2008, Seoul, Korea

Saeki, M., and Hori, M., (2006) Development of an Accurate Positioning System Using Low-Cost L1 GPS Receivers. Computer-Aided Civil and Infrastructure Engineering, Volume 21, Issue 4 pp 258-267. DOI: 10.1111/j.1467-8667.2006.00433.x.

Wong, K. Y.; Man, K. L.; Chan, W. Y.; (2001)Monitoring Hong Kong's Bridges, Real Time Kinematic Spans the Gap. J. GPS World, vol 12, No. 7, pp 10-18.

Yue, Q.; Wu, L.; Liu, H.; Huang, Y.; (2013) The Application of GPS in Dynamic monitoring on Longspan Bridges during the Operating Process. Proc 2nd Joint International Symposium on Deformation Monitoring (JISDM), Nottingham. 